\title{
On the Meaning of the History of Philosophy
}

\section{Philosophy and its History}

Philosophy has a history. Or, to put it more accurately, we can say that philosophy is in history and it has a history. Both elements constitute its historicity. It is, in its entirety as well as in every respective concrete form, in history, part of a comprehensive, temporal and factual history that precedes and exceeds it; and it has a history-its own history, that determines its character and its course. Philosophy shares this characteristic with other intellectual and cultural formations, with music, religion, the nation, football-in which both of these aspects of historicity also always exert their influence. These too are all historically situated and happen as history. Its particular history is part of a general history, the history of the collective, of the epoch, of culture, of humanity and, in other respects, of nature, of being.

\subsection{Philosophy's Relatedness to History}

Nevertheless, the realization that philosophy has a history is no triviality. This is because philosophy is historical and has a history in ways that differ from those of medicine or Baroque music (let alone the glaciers). Philosophy is a cultural formation that is essentially historical and this in the sense that it is not only factically rooted in history and historically conditioned but further in that it is constitutively related to its history. This is first of all a descriptive, distinctive characteristic of philosophy which conspicuously sets it apart from other sciences and cultural forms. A glance at philosophical research as well as at teaching, the conference calendar, publishing brochures, libraries and course catalogues sufficiently demonstrates this. Next to systematic themes and research questions of applied ethics up to ontology we find a many-sided pre-occupation with the history of philosophy as well as with individual authors and movements, epochs and with the history of philosophy as a whole. This kind of relatedness to history appears to be an essential characteristic of philosophy. However, it is an ambivalent and controversial basic feature of philosophizing. Historicity conflicts with philosophy's claim to truth, a claim which aims at a trans-historical knowledge that is not bound by the conditions of time. The separation of genesis and val- 
idity should uncouple the validity of an insight from its factical genesis. From the beginning philosophy maintains itself in opposition to relativism, to which belongs a return to subjective suppositions as well as to historiographical contextualization and to genealogical foundations. The tension between the claim to truth and consciousness of historicity appears to be inherent in prominent philosophical positions. The split manifests itself in the self-understanding of philosophy as well as in the external judgment of it. Respect and contempt for the historiographical stand immediately opposed in the conflict between purely systematic and historical-philological work. This conflict plays itself out between the apparent self-evidence of broad and highly elaborated historiographical research on the one hand and the critical rejection of classical readings as well as an equally differentiated conceptual-systematic discussion on the other.

It is a controversy that cannot simply be resolved by taking a strategic position for one or the other side. Even if this fundamental relatedness to history designates a controversial situation, it nonetheless stands for a distinctive and basic feature of philosophy that cannot be struck out unless one wants to engage in an arbitrary redefinition of the discipline. Philosophy, as a way of thinking that evolved historically and was shaped throughout its development by culture, is characterized by a strong relatedness to its history. It constitutes the overarching framework and lies at the basis of a common language within which philosophers negotiate their themes, articulate their hypotheses and contest opposing concepts; allowing for diversification and dissent, it makes possible a coherent expert discourse. The history of philosophy, as Wilfred Sellars says, forms the lingua franca of philosophy. ${ }^{1}$

\subsection{The Continuity of Philosophy}

At the same time, the relatedness to history is not only a controversial basic feature of philosophy but above all one that requires elucidation. This relatedness remains to be clarified, just as much as the question in which sense it is a constitutive element of philosophy. The historiography of philosophy is not external to philosophy; it does not occur as an auxiliary discipline, an external, optional supplement such as, for example, the way in which medical history is related to medical research. Rather, in classical concepts it becomes an integral part of philosophy itself (see, for example, Hegel). Externally its coherence manifests in the fact that the historiography of philosophy doesn't appear primarily in historio-

1 Sellars (1967), 1. 
graphical research or in the historiography of ideas in cultural studies. It is not studied primarily by historians but by philosophers. Philosophy writes its own history and does not hand it over to the professional expertise of historiographers. Likewise, the history of philosophy is read, interpreted and appropriated by philosophy itself. The historiography of philosophy stands for a specific reflexivity of philosophy, which relates in a specific way to itself in its relation to history. Elucidating this self-relatedness is an essential part of explicating the historiography of philosophy as well as of philosophy itself.

First of all a general characteristic must be identified which is associated with this self-relatedness in the medium of history. It can be located in the unusual continuity of philosophy. Even if the history of philosophy, as other cultural fields, is characterised by breaks, innovative new beginnings, diversions and losses, it is a fact that Western philosophy, which originated in Greece, is distinguished from other cultural creations through a progressive series of connections and references perpetuated through the epochs. It belongs not only to the oldest and most prestigious creations of this exceptionally creative epoch, in which many forms of European culture, artworks and sciences have their origin. Above all it is characterised by a unique kind of retrocursive relatedness both to earlier positions as well as to the beginning of the discipline and its history as a whole. The philosophers of late Antiquity, the Middle Ages and of the modern and contemporary eras work out their views and acquire their self-understanding by entering into dialogue with earlier authors and grappling with their own pre-history, a pre-history that they partly inherit and partly write anew, critically revise or dismiss. The pre-eminent meaning of the origin, namely the powerful impression Plato and Aristotle made on philosophical discourse is quite different to that made by the histories of Thucydides and Herodotus's on historiography or that made by Greek sculpture on the fine arts. The beginning not only had actual effects in subsequent history but it remains as that to which philosophy in the present attaches itself to or pushes off from. The communicative community in which every science develops in the case of philosophy expands from a synchronic to a diachronic dialogue with earlier generations.

\subsection{The Historicity of Spirit}

Why this is so remains to be clarified. The substantial, philosophical hypothesis which corresponds to these external characteristics of philosophy's relatedness to history and the continuity of philosophical discourse is that of the hypothesis of a fundamental historicity of thinking. In a pronounced fashion Hegel had worked this out in such a way that he doesn't read it as a form of temporal relativism 
but as an immanent historicity of reason. The historicity of reason and the rationality of history are contradictory indications, within this immanent intertwinement of philosophical thought and its history. The hypothesis of reason in history is obviously a strong one and rich in presuppositions, which Hegel believes to be the only $a$ priori to a philosophical theory of history. But this is not merely a precondition, he thinks, but a demonstrandum and a result of the accomplished and material meaning of world-history, at the same time. Historical knowledge had to prove that history happened rationally. It is a basic hypothesis that is also, in Hegel, affected by the immanent tension between historicity and the claim to truth. It is the ambivalence of a form of thinking and reflection that developed in time and appears with the claim to the highest knowledge since its beginnings.

In this context, the history of philosophy is up for debate in two respects. To draw on a conventional German conceptual distinction, even though it tends not to be used consistently, it concerns the "history" ["Geschichte"] and the "historiography" ["Historie"] of philosophy respectively. What is at stake here is the temporal development of the matter itself, of philosophical thinking, as well as its representation and reflective recollection. Both are essential for an understanding of the historicity of philosophy, and both became object of philosophical theories. These theories are interested in the way in which thought essentially develops in time, is based on what preceded it, takes this in and alters it, progressing according to laws or through ruptures and unpredictable innovations. But it also concerns how philosophy itself is retrocursively related to its past, how this past is recollected and interpreted, the latter being the function of the historiography of philosophy [Philosophiehistorie] for philosophy. When I referred to 'meaning of the history of philosophy' in the title of this paper, this formulation points in both of these directions. On the one hand, it can be understood as the question concerning how far the development of thought possesses an immanent meaning, a teleological tendency ${ }^{2}$ and on the other it can be understood as the question of what meaning and function the historiography of philosophy has for philosophy. The focal point of the following considerations is the second reading. I will not focus on considerations on the course of philosophical thinking throughout the ages but rather on questions concerning the logic and function of the recollection of philosophy. It concerns, schematically, the meaning of the historiography [Historie] and not of the history [Geschichte] of philosophy. However it should be noted that the two analytically distinct aspects-"history" and "historiography"-cannot really be detached from one another. This applies to both the history of worldly events as well as to the history of ideas. History is not

2 One such direction of questioning comes to fruition in Stekeler-Weithofer (2006). 
simply the objective course and totality of past facts. It is a course of events in so far as it is of concern for the "subject" in question, is important and present to it, if it is reflected by him and appropriated through him. By means of the unity of both aspects a distinction can be made between what is commonly called history (human history) and objectively occurring processes in nature (the "history" of the Alps or of the universe). Also for philosophical-historical reflection the reciprocal interference of both sides is important and to some degree it constitutes the very point of conceptual history. History becomes human history only insofar as humans become aware of it, grasp it and insofar as it becomes controllable through reason, at least ideally. According to Marx we only speak of real history when people take destiny into their own hands and themselves determine the conditions of life. ${ }^{3}$ Hegel envisions an even more radical entanglement of both sides when he situates the philosophy of history itself historically, claiming that the possibility of understanding history rationally is itself a result of the world-historical process of liberation. Firstmodern humanity is able to translate the rational claim of nature into the human world and to recognize the immanent ratio in the wealth of human productions. Both the philosophy of history [Geschichtsphilosophie] as well as the history of philosophy [Philosophiegeschichte] have, in this sense, their genuine place in the present.

\section{The Writing and Reading of History}

Before we further explore the function of the historiography of philosophy, the more fundamental question concerning its logic arises: in what forms and in accordance with what criteria does philosophy turn to its past and recollect its history? The logic of the historiography of philosophy, in this regard, embraces the logic of writing as well as that of reading, the construction as well as the reception of the history of thought-a unique entwining, which is based on the fact that that the historiography of philosophy on its part too is based on reading and practices a kind of reading. Similarly the question of the meaning of the history of philosophy encompasses the concerns of both side. Only a few aspects concerning the history of philosophy will be mentioned in the following.

3 Marx (1968), 546, 544, 570. 


\subsection{The Object of the Historiography of Philosophy}

First, the historiography of philosophy is confronted with the question of what its object is. More accurately it concerns the extensional question of what is to be counted as within the field of philosophy and its history. Normally the delimitation of a subject area pre-necessitates an undisputed definition of philosophy that decides to what extent a history of philosophy ought to consider poetry, medicine, law and theology, the natural sciences and myths. Classical german lexicons such as the Grundriss der Geschichte der Philosophie or the Historische Wörterbuch der Philosophie suggest different demarcations. Rather than adhering to the confines of academic disciplines and publications, Kurt Flasch suggests to focus on the argumentative substance of texts and to work with an open concept of philosophy that is to be tested concretely. ${ }^{4}$ At the same time the level on which philosophical thinking is or should be historically reconstructed is up for discussion. Historiographical studies are concerned with individual works and authors, with the development of concepts and problems, with currents, schools and epochs even including a comprehensive history of Western (or even human) thinking; and the approaches to this can be comparative, systematic or narrative-synthetic. A particular range, which the historical understanding of past philosophy covers, is that between intellectual work of individuals on the one hand and the "objective", trans-individual development of philosophical thought on the other. In this regard, Dieter Henrich ${ }^{5}$ distinguishes between the history of the genesis of significant works on the basis of drafts, revisions and editions which have become accessible in the past two centuries and which were not available before and the genesis of the philosophical insights of their authors, on the other hand, which evolve through the typical stages of the perception of a deficit and of a problem, of absorbing new perspectives in their relevance for the immanent theory and their relatedness to life, their lengthy elaboration, differentiation and review. According to Henrich, "constellation research" complements the study of the genesis of works. It integrates the individual work and the author into a network of contemporary and historical discourses and it traces the reciprocal challenges, suggestions, adaptions and disassociations in their entanglement. On the whole a genuine intertwining of inner and outer perspectives belongs to such reconstructions and it inscribes the individual conception in a comprehensive development and, inversely, brings claims to objective knowl-

4 Flasch (2005), 17-19.

5 Henrich (2011), 8. 
edge to bear on the historical position. For the epistemology of historiography, both are associated with open questions.

\subsection{The Unity and Diversity of Philosophy}

What is in question is the extent to which we are concerned with one and the same way of thinking, with one and the same project in exploring diverse developments. It is a question that analogously confronts the attempt to integrate a scattered sequence of events and settings into a regional, national or even human history. Historiographical philosophical construction too has to take into consideration breaks, innovations that are not merely derived from the preceding and paths that lead nowhere as well as developments and continuations related thereto, without refuting one by the other. On a structural as well as diachronic level it is confronted with the dichotomy of reference and distance, unity and heterogeneity. The balance between discontinuity and continuity is a question for concrete historiographical-philological research. The antagonistic and polemical character has been understood as an almost essential feature of philosophy as developing in conflict, a character that even becomes apparent to historiographical perception: for philosophical thinking maintains itself essentially in conflict with other, earlier views. ${ }^{6}$ However, connections between problems are also striking and the formation of schools and traditions right up to the periodization and classification of epochs belongs constitutively to the historiographical form of philosophy. Their definition remains a construction that is to be solidified or criticised within substantive work. Here the basic problem of diversity affects not only the synthesizing needed for attaining a unified form or narrative. It is, in its virulence, a provocation to the truth claims of philosophy. Such a plurality raises the question of how the conflict between systems is compatible with the claims to knowledge made by philosophy. This problem establishes an obstacle for philosophy's self-understanding in that it demands that the plurality of positions be treated along the lines of works of art and styles or understands philosophies as co-existing worldviews. Philosophy remains, even in temporal and spatial dispersal, one project of thought that is distinguished through its overriding will to knowledge and a singular internal relatedness.

6 Gueroult (1956), $47 \mathrm{f}$. 


\subsection{Historiographical Understanding}

Finally the question arises as to the kind of theoretical attention to history. In what way is the historiography of philosophy to engage the specific claim to truth of its object? The following answer suggests itself: it relates discursively-argumentatively to the concerned philosophy, whose claim to validity it takes seriously and discusses critically. Thus it is taken into account that, as a philosophical discipline, it belongs to the discursive continuum of its object. Another perspective is offered by the literary-historical approach in which the genesis, the statements and the character of philosophical documents are explained from the outside; in a similar way a psychological or sociological reading can extrapolate the contingency of past views instead of their internal validity. Viewed abstractly, here conceptual-systematic and external-historiographical perspectives are juxtaposed. However remaining in such dichotomies appears unsatisfactory for a historiographical understanding of philosophy. The historiography of philosophy cannot restrict itself to oscillating between either temporal relativism or truth independent of time, between anticipating the unfamiliar and a translation of the unfamiliar into the familiar. It operates in the in-between, in mediation between resisting both historical relativism and schematic de-historization. Its basis is the insight into the fundamental historicity of past as well as current knowledge. Historical contextualization does not mean the refutation of preceding opinions or even a suspension of the truth-claims of knowledge. According to Kurt Flasch "[C]ontingent conditions of genesis” do not refute an argument but "position it”; generally historiographical philosophy moves neither in trans-temporal nor in merely local formations but in rules and forms of thinking that are marked by a "medium duration and extension of validity". What is important in the historiographical analysis of ideas is to work out both the rational intelligibility of the formation of ideas and how it is comprehensible by external factors. It is precisely when positions are taken seriously in their truth claims that they can also be historiographically situated through critical judgment and can be interlinked with a certain perception of history.

Where this is the case ideas of a directed, teleological development, even rational progress, which Hegel saw as is inherent in history, can be registered. Still such "historization" does not necessarily need to be carried out with the sense of an emphatic supposition of rationality, much less be expanded to a putative overall course of the history of thought. Even "weaker" ways of reading, ways which are less rich in presuppositions, provide a genuine historiographical intel-

7 Flasch (2005), 51, 70. 
ligibility that illuminates both the individual work and the standpoint of current thinking. Such readings can emphasize the connections and interrelations of historical concepts and thereby not only span different times and spaces but take into consideration connections in their different modalities of receptions and criticisms, traditions and projects, variations and further continuations. Beyond the alternative of disillusionment and legitimation such reconstruction provides a historiographical knowledge that has not only object-related relevance. Historiographical philosophical consideration concerns philosophy's own reflectiveness. Philosophy becomes self-aware in its reflection on its history ${ }^{8}$. To clarify the form and content of this hypothesis, it must be considered within the horizon of the general question of the function of historiographical philosophy.

\section{The Meaning of the Relatedness to History}

Why should it not be possible to engage in philosophy in a strictly subject related manner, independently of historiographical references? What is the central importance, the possibly indispensible function of the historiography of philosophy, its own non-contingent interest in its history? Not only the actual writing of the history of philosophy are at stake here but also the different forms of the relatedness to history in philosophical work, from a cursory reference to historiographical positions, schools and trends in a thematic context, the reconstruction of works, theoretical coherences and traditions right up to the philosophical interpretation of ways of thinking as a whole. Obviously, the form and frequency of such references vary greatly in the course of epochs, but seen as a whole, one can speak of a growth in historiographical reflections of thinking, even if this growth is not continual or linear. However, this does not mean that that its motive and necessity would become in equal measure more clear and precise. It seems to me pointless to attempt to subsume the different kinds of interest in the historiography of philosophy under one guiding idea. I propose to distinguish the external relation to the historiography of philosophy (III.1) from the internal, constitutive relatedness to history of philosophy and to differentiate the latter according to three approaches. (III.2-III.4). ${ }^{9}$

8 Such is a leading thesis of Stekeler-Weithofer (2006, 229) and Flasch (2005, 72); see III.4 below. 9 The following draws partly on observations in Angehrn (2002). 


\subsection{History as a Quarry of Ideas}

The most unproblematic interpretation, at least to a certain extent, considers the history of philosophy, as Hegel put it, as a "stock of opinions". ${ }^{10}$ History is a fund of theories, ways of apprehending, concepts and arguments, that current work in philosophy and representatives of the subject can draw upon by virtue of their professional competence. Current debates can rely on historiographical examples for the purposes of illustration, for the exploration of a thematic field and the testing of solutions: in earlier theories explanations of concepts, argumentative strategies, aporiai and suggestions for solutions were explored which present work can draw upon and can gain a sense of direction from, concerning certain difficulties and prospects of certain ways of thinking.

Likewise, the history of philosophy can become a privileged medium of initiation and teaching. While the introduction to technology and the natural sciences occurs through praxis and the appropriation of basic principles, which both are also essential for philosophy, the latter further proceeds via a familiarisation with classical texts and discussions. Likewise, this ties communication to a common frame of reference which the formulation that historiography is the lingua franca of philosophy indicates. The resorting to and command over shared references (authors and concepts) is the precondition of any engagement, examination or debate in systematic discourse.

All this describes characteristics which explicate the manifest and close connection between philosophy and the history of philosophy. Historiography as a resource and a frame of reference sustains and regulates philosophical work. But it is a bond that, so to speak, which remains external and does not determine the philosophical way of thinking in its core. It remains to clarify in what sense philosophy draws upon past theories and positions not only as material or as an external frame but in the sense that it appropriates them as its own inner substance and in how far history forms a dimension of its own, forms a medium in which it situates itself and takes place as itself. To this end, we can distinguish three perspectives.

\subsection{Historical Foundation and Argumentative Discourse}

Philosophy is intertwined in a narrower way with history where historiographical reflection touches upon the question of truth. The truth of past as well as present

10 Hegel (1970), 28-36. 
thinking stands in question here. In a negative form this nexus strikes us as historiographical relativizing: facing the fact of its origination in the past, the diversity and mutability of thinking amounts to a calling into question, or at least to an indication of the contingency of one's own standpoint. Historicism is the basis of relativism and, further, every doctrine that wants to present itself as having an absolute claim to validity seeks to situate itself outside of history or to construe history as a development that is completed with its own appearance and which is external to the validity of its results. That philosophy has a history initially appears to be a suspension of its own truth. Hence what suggests itself here is an attempt to posit the selfauthorization of reason as an abstraction from history, for example through a methodological doubt as the forgetting of all tradition. ${ }^{11}$

This contrasts with the opposed idea of the relatedness to history functioning as an authentication of philosophy, as a legitimating "proof of origin". ${ }^{12}$ This can be the case with varying degrees of stringency. In the most general way insertion into a history, the connection to predecessors and the appeal to authorities constitutes a mode of legitimation in both practical and theoretical respects. Such a basic "tradition oriented" justification is familiar from the life-world and is established in both a science-theoretical and hermeneutically regards, but nonetheless can be still questioned. Its problematic adheres to philosophy in the contrast between emphatic truth and the constitutive relatedness to tradition. One answer to this aporia is presented by the philosophical-historical self-assurance of thinking which grasps the present as the destination of a history that comes to its truth and its conclusion in it. An exemplary implementation of this is achieved in Hegel's reading of history as an affirmative self-explication and legitimation of spirit. History as the occurrence of truth and the philosophy of history as theodicy are the conceptual stamp of such a foundation. But even in weaker versions the founding upon history can be articulated. Such can be seen in Aristotle's endeavour to support his own theories by appealing to the consensus hominum et temporum. A minimal premise of such types of argumentation is represented in the unity of history: the fact, that the progress of philosophical thought in the change of themes and dogmas is also understood as one development, in which the scattered voices are related in criticism and continuation. But what is essential for the potential for truth of such connections is that this is carried out as an argument and discussion with history that is oriented towards what is valid. What matters most centrally here is a discursive examination that is oriented to the matter itself, that includes past positions as well

11 See Beelmann (2001), 15.

12 Beelmann (2001), 15. 
as contemporary statements in a dialogue rather than fixing them in a historicizing manner as facts and understanding them as certain convictions or as the results of developments. In such an attitude of a reflective historiography of philosophy, as distinguished from cultural-historical writing, past documents are interpreted in their claim to validity.

Not least is the insight into the historicity of knowledge of importance here, which does not intend a mere relativism. Rather it is aimed at integrating itself into a history and thus makes possible a discussion between different positions across times and spaces. It bridges the alleged incommensurability of divergent ways of understanding in that it opens them towards each other from out of overarching contexts. Thus it does not level down all claims to validity but on the contrary enables the discourse of legitimation and critical comparison. Historical consciousness is the pre-condition of a disclosing understanding as well as a rational and evaluating reference wherein the genetic reconstruction sustains critical examination of rational claims and, inversely the reflection on validity sustains the moment of the disclosing of meaning.

\subsection{Remembrance and Continuation of Writing}

The historiography of philosophy has, like cultural history in general, a purpose insofar as it participates in history: to keep the past alive and continue humanity's conversation into the future. Remembrance is a leitmotif of historical retrospection. In certain ways, this thrust of historiography approaches that which seems strangest to a philosophizing focused on the present: the retaining and cultivation of the by-gone for its own sake. It is the piety of preservation that Nietzsche attributed to what he calls the antiquarian historiographical attitude. Taken for itself it will not be primarily regarded as a constitutive moment of philosophizing. However it is thoroughly intertwined with the intrinsic motives of philosophical thinking. Philosophy shares in the dynamic of historicity, rooted in the fact that it can be addressed by the past and can respond to questions that the past directs at it. Derrida has emphasized that philosophical writing partakes of a duty to the past and relinquishes a debt to it: a debt towards the unsaid, the submerged and the displaced. Insofar as philosophy is confronted with this duty, it is interested in history for its own sake. By connecting to the past it discloses latent potentialities of the past that have not been voided and continues to write a history that was inherent in it but was not explicated. It continues a conversation whose historical radicality is not only related to the past but in equal measure reaches towards the future. As Rorty says, it is the highest task of philosophy to keep humanity's conversation from breaking off. When philos- 
ophy turns to its own history there is an irreducible interest not only in knowledge but in remembrance as such. In this, philosophy is both part of and an outstanding instance of historiographical culture as such.

\subsection{The Historical Self-Understanding of Philosophy}

In addition to discursive discussion and the remembering of tradition, historiography serves self-orientation and self-understanding. It is not only the truth of projects and concepts that is in question in the dialogue with the past; what is also of interest are its content and horizons of meaning, the directions of its questioning and its presuppositions. It is necessary to understand oneself in hindsight and to win clarity about one's activities and research. I want to specify this-deepest and most extensive-orientation of the interest in history from three angles.

On the one hand the historiographical perspective promotes better understanding insofar as it can elucidate the past evolution and the broader context of that understanding. This task is central in relation to thinking and the course of its development. We better understand a hypothesis, an argument, an intention when we trace the context of problems to which it responds, what experiences underlie them, and possibly in what ways it assimilated earlier formulations and attempts at solution which are hidden within it or only readable in traces. Historical analysis can reveal layers that remain concealed to direct descriptive access. This is true for the understanding of the other as well as the understanding of itself. Historical background and the genetic perspective allow a deeper understanding of cultural formations for both its subjects and for external observers.

On the other hand historical reflection serves not only a retrospective (self-) understanding but also prospective self-discovery. It is not only about an appropriate interpretation of a traditional teaching, but about ascertaining from the dialogue with the past what we are getting at in our own research and what we ask after in our work. Here the driving motivation is not the corroboration of the answer but the clarity of the question.

We find an eloquent testimony to such self-orientation through dialogue with the past in the earliest phase of philosophy. Aristotle's Metaphysics, a classical and fundamental work of the discipline named after it, does not propagate any speculation about first and last things. Rather the whole first book is devoted to determining what its concerns and objects are. The "science that it sought for"-as the guiding principle of the discussion-is gained via a pre-meditation of the highest, most eminent knowledge on the one hand and on the other through conversations with predecessors, with the Pre-Socratics and Plato. Their approaches are explored and elucidated so as to provide a twofold 
proof, namely that they all researched into first causes and principles and that this research operated within the framework of Aristotle's conceptualization of the four causes. From this the project of a first philosophy received its concretion and its historiographical attestation and authentication. The remark that the older thinkers worked on the project put forward by Aristotle but without expressly knowing it is revealing: First they dealt with what, with hindsight can be seen as their true concern, in a way that was "obscure", "stammering" and "unclear". ${ }^{13}$ Philosophy gains a sense of its own path not by looking back at an initial foundational act but in conversation with a way of thinking that is still unsure of itself, a tentative beginning, that for its part first gains its clear orientation in extrapolation.

The opening book of the Aristotelian Metaphysics is exemplary insofar as it refers to the structural problem of beginning and first ascertains its goal while looking back at pre-history, out of which this self-ascertainment occurs. Such retrospection is essentially hermeneutical, intertwining understanding and communication, the exegesis of the origin and the act of beginning and self-orientation are intertwined. This consciousness of origin corresponds to a hermeneutic characteristic, which is likewise emphasised within deconstruction, insofar as it goes back to a tentative, underdetermined origin, not an underlying Eidos or an identifiable "primal foundation" which contains progress as a telos which is to be unfolded. Even without the support of a substantialist philosophy of history with firm original, developmental and purposive guidelines, historical reflection functions as the medium of self-understanding and self-discovery.

What the Aristotelian example illustrates with regard to the self-definition of philosophy can be analogously applied to particular themes and questions. Attention to history contains a hermeneutic-heuristic potential that aids communication about the content, the direction, the premises and the problems of certain questions. Questions concerning the immortality of the soul or the historicality of science, concerning the limits of the state or the legitimate grounds of subjective freedom are not, at all times, taken seriously as questions or even understood. Many leading concepts of philosophy are historically and culturally situated concepts in that they emerge and are worked out, modified and differentiated in a certain real and ideal historical framework and, as the case may be, fade and dissolve. To become conscious of its historicity belongs to the elucidation of its content and direction and impacts the negotiation of topics that have been treated in current discussions. Current philosophy does not simply realize itself from out of the present. It is not exhausted in the sum of current knowledge; its

13 See Aristotle, Met. I.4, 985 a 5-18; I.7, 988 a 18-23; I.10, 993 a 12-17. 
"state of the art" is grasped deficiently when cut off from history. Philosophical theories and their objects are, to a wide extent, historically impregnated and cannot be adequately grasped in their content and applied without explication of this historiographical density. Historiography is not only an external so to speak technical contribution to conceptual work but a way of penetrating into its material and self-orienting in one's own research.

A particular aspect of such communication is that in the historiographical look the external perspective acquires validity. History is the medium in which I encounter the strange but also the dimension in which I perceive myself from outside, from the other. In a particular way historiographical reflection is the medium of self-understanding where it is confronted with what was suppressed, marginalized or shut out in the history of thought, where it re-endows self-consciousness with what had been lost to it, what had been forgotten within it. In this sense Husserl's Crisis makes manifest the life-world as the forgotten fundament of meaning for science through historical retrospection. History works out the repressed of this history, becomes aware of what is other to this history itself. A form of thought can in the reconstruction of its genesis win an adequate understanding of its uniqueness, its determining motives and also its limits; philosophy can become aware of what, in its dominant form, was pushed back (non-European, female, non-academic philosophy) and of what remains unthought in its concepts (corporeality, nature, ontological difference). The relatedness to history is situated, in all of this, in the horizon of a self-enlightenment of philosophy-a deeper understanding of its self-definition as well as its motives, leading concepts and open questions.

\section{Conclusion}

History is the medium of self-knowledge. What humanity is, according to Dilthey, is recounted by history. What philosophy is, is revealed by its history; the historiography of philosophy as its reflexive recollection is the becoming self-conscious of philosophy, its accountability towards itself and its self-enlightenment. One can put the emphasis in this process more firmly on history or on historiography. Following a suggestion of Pirmin Stekeler-Weithofer, the course of philosophical thinking could be thought as a coherent developmental-process of the spirit in which initial open-endedness and ambivalences of the forms of human understanding are gradually resolved-not necessarily as a lawful and necessary higher development towards complete and perfect truth, but rather as a process 
of gradual self-clarification and disambiguation of thinking. ${ }^{14}$ Correspondingly, the reflexive recollection of these processes can on its part be understood as a mode of self-knowledge and this, according to Kurt Flasch, can be understood as the motive and actual meaning of the historiography of philosophy. ${ }^{15}$ Walter Jaeschke combines such self-knowledge with Hegel's paradigmatic claim about unity of philosophy and history of philosophy and reads this in terms of the reflexivity of philosophy. Philosophy has its truth, according to Hegel, ultimately in the absolute self-relation of thinking, as he lays out in the three conclusions at the end of the Encyclopaedia as three forms of philosophy's turning back to itself -to the forms of the absolute spirit, to the systematic representation of philosophical sciences and to the history of philosophy which, although to Jaeschke, there is no doubt that the last "historical form [is] comprehensive and fundamental." ${ }^{16}$ The retrospective glance to the history of thinking, as a looking back to spirit's self-knowledge, is "if not the only, but the highest form of noesis noeseos." 17

However, such self-relation does not necessarily need to be conceived in terms of a complete self-transparency of spirit in the Hegelian sense-an ideal that has become alien to today's thinking. Also quite independently of this it can stand as a vanishing-point in the reflexivity of spirit and its historical becoming conscious. Also what was for Hegel a further intertwinement between the history of spirit and its historiographical reflection remains at least as a question and as a task for current thinking, independently of Hegel's absolutization. According to Hegel it is itself a fact of history that the historiography of philosophy in the present has become possible and necessary: Only the modern subject which is able to grasp itself in the world is able at the same time and prompted to recognize itself in its thinking and willing. The genesis of the historiography of philosophy is itself an index of the progressive status of the history of philosophy, the historical self-explication of spirit; historical-reflectiveness belongs to the historicality of thinking. The question remains, to what extent this step to the becoming historical of thinking is irreversible. If post-metaphysical thinking raises the issue of the constructiveness of the world and its self, it remains to be seen to what extent its own history becomes increasingly present and easier to access-or slips away from it and becomes abstract, without interest for it.

14 Stekeler-Weithofer (2006), 229-231.

15 Flasch (2005), 72.

16 Jaeschke (2000), 500.

17 Jaeschke (2000), 501. 


\section{Bibliography}

Angehrn (2002): Emil Angehrn, “Wozu Philosophiegeschichte?”, in: Emil Angehrn and Bernard Baertschi (Eds.), Philosophie und Philosophiegeschichte. La philosophie et son histoire, studia philosophica vol. 61/2002, Bern / Stuttgart / Wien: Haupt, 37-65 (also in: Emil Angehrn, Wege des Verstehens. Hermeneutik und Geschichtsdenken, Würzburg: Königshausen \& Neumann 2008, 111-134)

Beelmann (2001): Axel Beelmann, Theoretische Philosophiegeschichte. Grundsätzliche Probleme einer philosophischen Geschichte der Philosophie, Basel: Schwabe.

Flasch (2005): Kurt Flasch, Theorie der Philosophiehistorie. Philosophie hat Geschichte, vol. 2, Frankfurt a. M.: Klostermann.

Gueroult (1956): Martial Gueroult, “Le problème de la légitimité de l'histoire de la philosophie”, in: E. Castelli et al., La philosophie de l'histoire de la philosophie, Paris: Vrin.

Hegel (1970): G.W.F. Hegel, Vorlesungen über die Geschichte der Philosophie I, in: G.W.F. Hegel, Werke in zwanzig Bänden, vol. 18, ed. by E. Moldenhauer and K.M. Michel, Frankfurt a. M.: Suhrkamp.

Henrich (2011): Dieter Henrich, Werke im Werden. Über die Genesis philosophischer Einsichten, München: Beck.

Marx (1968): Karl Marx, Philosophisch-Ökonomische Manuskripte, in: Marx Engels Werke, Ergänzungsband I, Berlin: Dietz.

Sellars (1967): Wilfrid Sellars, Science and Metaphysics. Variations on Kantian Themes, London: Routledge and Kegan Paul (1967) / Atascadero: Ridgeview (1992).

Stekeler-Weithofer (2006): Pirmin Stekeler-Weithofer, Philosophiegeschichte (Grundthemen Philosophie), Berlin: De Gruyter.

Jaeschke (2000): Walter Jaeschke, "Philosophie und Philosophiegeschichte”, in: Hermann Drüe et al., Hegels 'Enzyklopädie der philosophischen Wissenschaften' (1830). Ein Kommentar zum Systemgrundriss, Frankfurt a. M.: Suhrkamp, 487-533. 
Bereitgestellt von | Universitaetsbibliothek Basel Angemeldet

Heruntergeladen am | 31.05.16 15:00 